\title{
Questioning the assumptions about type 2 diabetes
}

$\mathrm{T}$ wo key assumptions that underlie clinical practice guidelines for type 2 diabetes have resulted in a vast increase in the number of patients receiving multiple lifelong therapies. ${ }^{1.2}$

The first assumption is that type 2 diabetes is a progressive, irreversible condition that is diagnosed on the basis of blood glucose level exceeding a single threshold on one of three tests. One of the thresholds is based on observational studies that show that at a fasting glucose level of $7.0 \mathrm{mmol} / \mathrm{L}$ the prevalence of retinopathy begins to increase. ${ }^{1,2}$ This diagnostic definition does not recognize the continuous relation between glucose and the risk of complications $^{3}$ or the contribution of other factors such as duration of dysglycemia, age, comorbidity, genetics and etiology. For instance, a 57-yearold obese man with hypertension and a fasting glucose level of $15 \mathrm{mmol} / \mathrm{L}$ has a very different prognosis than a healthy 75 -year-old woman with a fasting glucose level of $7.1 \mathrm{mmol} / \mathrm{L}$.

The second assumption is that therapies that lower glucose levels will benefit all people who receive a diagnosis of type 2 diabetes, and that the benefits are realized only after a specific glucose target is met. Although recent guidelines allow for higher targets in patients with multimorbidity and limited life expectancy, intensive glucose control and a glycated hemoglobin (HbA1c) target of $7 \%$ or less is recommended for most patients. ${ }^{2}$ Evidence shows that the benefit of this approach is modest at best, ${ }^{4}$ and the incremental benefits of treatment depend on the baseline glucose level. Data from the United Kingdom Prospective Diabetes Study ${ }^{5}$ show that the 10year complication risk for a 50 -year-old white man with an $\mathrm{HbA} 1 \mathrm{c}$ of $10 \%$ is $12.5 \%$. If this patient achieves an $\mathrm{HbA1c}$ of $8 \%$, the risk will be substantially reduced, to $6.6 \%$. Nevertheless, physicians are encouraged (some are even offered financial incentives) to achieve an $\mathrm{HbA1c}$ of $7 \%$ in their patients, which

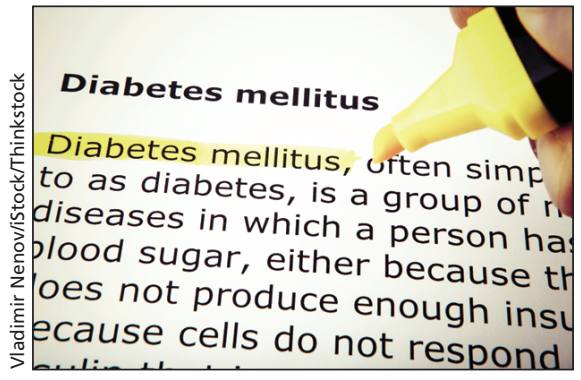

for this patient, would only further reduce the risk, to $4.9 \%$. Patients whose $\mathrm{HbA} 1 \mathrm{c}$ levels remain above the target may face the psychological burden of being considered treatment failures.

To lower their HbA1c level from $8 \%$ to $7 \%$, patients are usually required to make more intensive efforts, which include taking more medications (which increases the risk of adverse effects, such as hypoglycemia and weight gain), self-monitoring glucose levels and dealing with increased health care visits.

These assumptions need to be challenged for three reasons. First, although diabetes treatment is essential for many patients to alleviate their symptoms and help them avert complications, some patients are labelled and treated without clear benefit while being exposed to potential harms. Second, the patientborne financial costs for medication and supplies are substantial, ranging from $\$ 1000$ to $\$ 15000$ per year. ${ }^{6}$ Third, the growing number of people who receive diagnoses and treatment for type 2 diabetes is causing an unprecedented burden on health care systems. The annual direct cost of diabetes in Canada is about $\$ 12$ billion, which accounts for $3.5 \%$ of public health care spending. ${ }^{6}$

Why do these assumptions prevail? Overinclusive practice guidelines align with the natural tendency of physician experts to ensure that no patient who could potentially benefit from intervention is missed. We also argue that the pharmaceutical industry reinforces these assumptions to maintain a stable and growing demand for medications.
Although pharmaceutical companies have traditionally focused on marketing specific products, there is an increasing shift toward expanding the definition of treatable diseases as a way to enlarge the market. ${ }^{8}$

Generously funding the societies that produce guidelines, which we believe may be clever marketing disguised as philanthropy, is a means by which the industry can shape prescribing practices. ${ }^{7}$ Further, about $94 \%$ of authors of diabetes guidelines have declared pharmaceutical relationships. ${ }^{9}$ Although most authors do not explicitly recognize their conflicts of interest, evidence shows that their opinions and practice patterns are nonetheless influenced by these relationships.?

We need to think differently about type 2 diabetes. The diagnostic definition and treatment targets should be based on baseline risk of complications, not on specific glucose thresholds, and the benefits of treatment should be considered in the context of potential costs and harms. Because these changes may lead to a reduced number of medications prescribed to fewer people, the societies that develop and authors who write clinical practice guidelines need greater independence from pharmaceutical companies.

\section{Lorraine L. Lipscombe MD MSc \\ Allan S. Detsky MD PhD \\ University of Toronto \\ Toronto, Ont.}

Acknowledgements: The authors thank David N. Juurlink MD PhD and Baiju R. Shah MD $\mathrm{PhD}$, both from the University of Toronto, who provided comments on an earlier draft. Neither received compensation for doing so.

See references, www.cmaj.ca/lookup/suppl /doi:10.1503/cmaj.140541/-/DC1

CMAJ 2014. DOI:10.1503/cmaj.140541

Do you have an opinion about this article? Post your views at www.cmaj.ca. Potential Salon contributors are welcome to send a query to salon@cmaj.ca. 